\title{
Glacier recession on Kilimanjaro, East Africa, 1912-89
}

\author{
Stefan Hastenrath, Lawrence Greischar \\ Department of Atmospheric and Oceanic Sciences, University of Wisconsin, 1225 West Dayton Street, Madison, Wisconsin 53706-1490, U.S.A.
}

\begin{abstract}
The varying ice extent on the Kibo cone of Kilimanjaro, East Africa, this century was reconstructed from terrestrial-photogrammetric mappings in 1912 and 1953 and satellite images in 1976 and 1989. These were all conformed to the official 1:50 000 topographic sheet. The ice distribution on Kibo is characterized by lower ice margins on the southern than on the northern flanks, and deepest-reaching glaciers to the west contrasting with least ice cover on the eastern crater rim. The meridional contrast appears to be related to the more abundant precipitation on the southern side. The even more striking zonal asymmetry in ice cover is favored by the vigorous diurnal circulations, with enhanced afternoon cloudiness blocking insolation on the western slopes. The total ice cover diminished from 12058 to 6675 to 4171 to $3305 \times 10^{3} \mathrm{~m}^{2}$ between the vears 1912, 1953, 1976 and 1989, and the three large coherent ice bodies disintegrated into numerous smaller ice fragments.
\end{abstract}

\section{INTRODUCTION}

In international global-change monitoring efforts it is increasingly being recognized that tropical glaciers are a particularly sensitive component of the climatic environment (World Meteorological Organization, 1988; Haeberli and Hoelzle, 1993; Hacberli and others, 1993). Glaciers near the Equator still exist in the Andes, in New Guinea and on three high mountains in East Africa. All glaciers in the tropical zone have suffered drastic ice wastage over the past 100 years (Hastenrath, 1981, 1984). The present study combines historical photogrammetric surveys with recent satellite measurements to reconstruct the ice retreat on Africa's highest mountain. The physiographic and climatic setting is reviewed in section 2; the observational sources and their evaluation are described in section 3; the characteristics of the spatial distribution of the glaciers, the pattern of retreat and the radiational forcing are discussed in sections 4 and 5; and a synthesis of the results is offered in section 6 .

\section{PHYSIOGRAPHIC AND CLIMATIC SETTING}

The Kilimanjaro massif, located less than $3^{\circ}$ south of the Equator, rises from a lowland plain to a broadly zonally oriented plateau-like base around $4000 \mathrm{~m}$ (Fig. 1). On this sit three separate peaks. The easternmost, Mawenzi, features sharp crests and precipitous faces. A broad saddle separates it from the main peak, Kibo. This nearly perfectly symmetric volcanic cone and the crater are broken only by the "Great Breach" in the western sector. To the west of Kibo extends the Shira Plateau, which contains a third, very minor peak. Moraine morphology attests to a formerly much larger ice cover extending to below the rim of the plateau (Hastenrath, 1984, p. 50 -53). Mawenzi still carried perennial ice in a small cirque until the 1930s (Hastenrath, 1984, p. 63-92). Apart from this, the recent glaciation is essentially confined to the Kibo cone of Kilimanjaro.

The large-scale circulation over East Africa is charac-

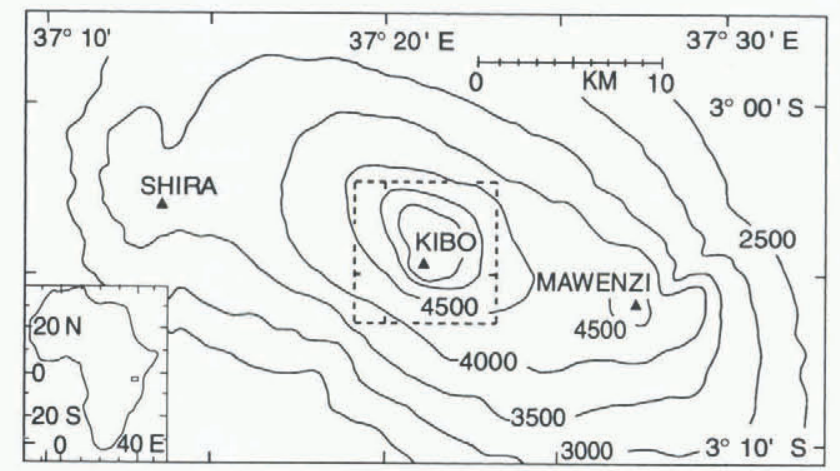

Fig. 1. Orientation map of Kilimanjaro massif showing Mawenzi and the cone of Kibo, with quadrangle delineating the map domain of Figures 2, 4 and 5. Height contours are at $500 \mathrm{~m}$ intervals; scale is 1:500 000. Inset map in lower left corner shows location of Kilimanjaro within Africa.

terized by a double passage of the Equatorial trough, with a northeasterly monsoon flow prevailing over the Indian Ocean during boreal winter, and a southeasterly flow in summer (Hastenrath, 1991). In the Kilimanjaro area the main rainy season lasts from February to May, with a secondary peak in October-November. The largest rainfall amounts are found on the southern slopes of the massif, facing the southerly monsoon (Coutts, 1969). The altitudinal belt of maximum rainfall, in excess of $2000 \mathrm{~mm} \mathrm{a}^{-1}$, is below $2000 \mathrm{~m}$. Precipitation decreases drastically towards higher elevations, with values dropping to $<250 \mathrm{~mm} \mathrm{a}^{-1}$ on the desertic Saddle Plateau. A stratiform cloud deck is frequently found, with an upper limit around $3000-3500 \mathrm{~m}$. Weather in the higher reaches of the mountain is strongly controlled by the vigorous local, diurnal circulations. Winds blow down the mountain from evening through the night into the middle of the morning, and skies tend to be clear. A reversion to up-slope winds occurs in the late morning and this brings cloudiness and precipitation which increase in 
the afternoon. The elevation of the annual mean $0^{\circ} \mathrm{C}$ isothermal surface is around $4750 \mathrm{~m}$.

\section{DATA AND EVALUATION}

The observational basis for this study consists of two maps from the early and middle parts of this century, four satellite images in recent decades, and the official topographic sheet (OTS; Tanganyika Government, 1972). While sketches are preserved of the ice extent at the end of the 19th century (Meyer, 1890; Hastenrath, 1984, p.70-72), the first precise mapping of the entire Kilimanjaro massif was produced by Oehler and Klute in May-October 1912 (Klute, 1914, 1920, 1921; Klute and Oehler, 1922), using terrestrial photogrammetry and at scale 1:50000. Likewise by terrestrial photogrammetry and in part relying on the terrain control established by the Klute expedition, Humphries (1953) mapped the glaciers of Kibo in July-September 1953 at scale 1:25000. A search of recently declassified intelligence satellite photographs from the 1960s yielded no suitable images of Kilimanjaro. The details of the four Landsat scenes are as follows: 24 January 1976, Landsat 2 Multispectral Scanner (MSS) bands 4-7; 21 October 1981, Landsat 3 MSS bands 4-7; 20 October 1986, Landsat 5 Thematic Mapper (TM), all seven bands; and November 1989, Landsat 4 TM, all seven bands. These satellite scenes were acquired from the Earth Observation Satellite Company (Eosat) and processed by the Hughes-STX Corporation, both in Lanham, Maryland, U.S.A. The OTS (Tanganyika Government, 1972), at scale 1:50000, provided the reference coordinate system.

Initially, a digital terrain model at $25 \mathrm{~m}$ cell size was constructed from the OTS, using the UTM projection, Clarke 1880 Ellipsoid, with northwest corner $305512.5 \mathrm{E}$ and $9668257.5 \mathrm{~N}$, and southeast corner $333337.5 \mathrm{E}$ and $9649857.5 \mathrm{~N}$. Following the procedure described by Marvin and others (1987), the four satellite subscenes were made to conform with the terrain model, using terrain features, such as peaks and stream junctions, identifiable on both the OTS and the satellite image. For 1986 and 1989 the same 11 ground control points were used; for the 1976 image 19 points; and for the 1981 scene 14 points. For 1976 and 1981 few of the points were common to two or more images. Of the four scenes, those of 1976 and 1989 proved to be of adequate quality for the present purposes. The 1981 image helped to delineate the northern ice margin that was partly obscured in the 1976 scene.

While the satellite scenes were thus made to conform to the coordinate system of the OTS, the transformation of the historical 1912 and 1953 maps posed various difficulties: (i) They possess only lines indicating one latitude and one longitude, but with no definite reference to the OTS. (ii) The northing of the 1912 map, and correspondingly of the 1953 map, appears rotated by about $5^{\circ}$ eastward with regard to the OTS, as is apparent from the alignment of recognizable terrain features. (iii) The 1912 and 1953 maps also contain some distortions in the horizontal, evident from the scaling of distances between pronounced terrain points in these maps and the OTS. In a first step, the 1953 map was matched to the OTS by applying a rotation in the northing and using 10 terrain points common to both maps. The resultant ice boundaries were then delineated to be consistent with the 1976 satellite image in location and orientation of the glaciers. The 1912 map was similarly matched to the OTS, applying a rotation of the northing and using $15 \mathrm{com}-$ mon terrain points, including the 10 used for the 1953 map. The resultant ice boundaries of 1912 were then adjusted to be in location and orientation of the glaciers consistent with the boundaries obtained for 1953.

\section{DOCUMENTATION OF ICE EXTENT}

This reconstruction of varying ice conditions is concerned with the Kibo cone of Kilimanjaro. In fact, the small patch of perennial ice on Mawenzi disappeared around the 1930s, as explained in section 2. Figure 2 and Table 1 present the nomenclature of ice entities of Kibo in the 1970s. The early history of glaciological exploration has been reviewed in more detail elsewhere (Hastenrath, 1984, p. 63-92). Meyer undertook expeditions to the glaciers in 1887, 1889 and 1898

Table 1. Nomenclature of ice entities on Kibo. Numbers refer to Figure 2

\begin{aligned} & \hline 1 Eastern Ice Field \\ & 2- \\ & 3 Ratzel Glacier \\ & 4 Southern Ice Field \\ & 5 Rebmann Glacier \\ & 6 Decken \\ & 7 Kersten \\ & 8 Heim \\ & 9 Furtwängler \\ & 10 Diamond \\ & 11 Balletto \\ & 12 Great Barranco Great Breach) \\ & 13 Little Barranco (Little Breach) \\ & 14 Arrow \\ & 15 Uhlig \\ & 16 Little Penck \\ & 17 Great Penck \\ & 18 Drygalski \\ & 19 Credner \\ & 20 Northern Ice Field \\ &\end{aligned}

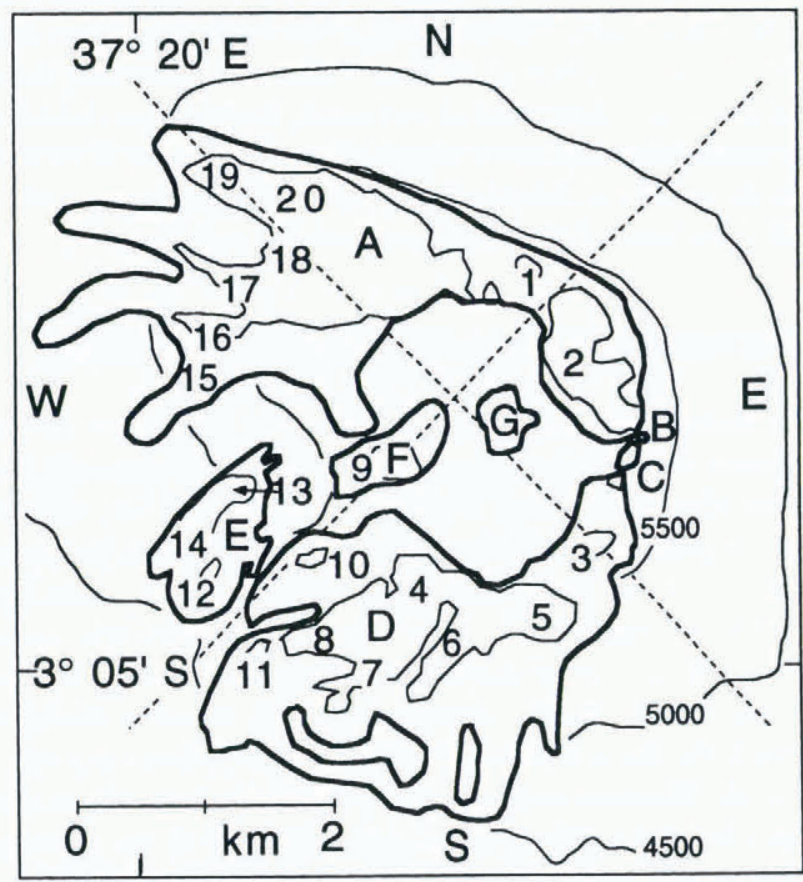

Fig. 2. Mapshowing the ice entities A-G in 1912, and 1-20 in 1976 ( see Table 1); and the division into quadrants north, south, west and east. Height contours are at $500 \mathrm{~m}$ intervals; scale is $1: 100000$. 
(Meyer, 1890, 1900). He encountered a continuous ice cover all around the crater rim, which made entry to the interior of the crater difficult. During his 1887 and 1889 expeditions he observed the progressive development of a depression in the eastern ice rim, the Hans Meyer Scharte (notch). By 1898 another incision, the Johannes Scharte, had formed somewhat to the south and was full of ice and snow. By 1904 the two notches were fully developed Hastenrath, 1984, p. 69-70). These are clearly recognizable on Meyer's (1900) sketch-map of a few years earlier, reproduced here as Figure 3. By 1912 (Klute, 1920) a third incision, the Leopard Notch, appeared between the Hans Meyer and Johannes notches. This brings us to the first photogrammetric survey available for the present study.

Figure 4 maps the ice cover on Kibo for four dates, reconstructed as described in section 3. Remarkable in the first place are the large ice-free areas in the approximately horizontal surfaces of the crater. Given the symmetric shape of this volcanic cone, the asymmetry of the ice distribution is striking. Glaciers are more extensive on the south than on the north. Even more pronounced is the contrast between the smallest ice extent at the eastern crater rim and the lowest-reaching glaciers in the western sector. This general pattern has persisted throughout the 20th century. The more abundant precipitation on the southern side of the massif appears to be a major factor in the meridional contrast in ice extent. Also, the location of the mountain to the south of the Equator is conducive to larger insolation on the northern flanks. The much more pronounced zonal contrast in the ice cover shows no relation to the spatial pattern of precipitation. The role of enhanced afternoon cloudiness due to local diurnal circulations (see section 2), and its effect in blocking the solar rays on the western flank, is modeled in section 5 .

Turning now to the long-term variations in ice cover, the extents for four dates during the 20th century are mapped in Figure 4 and listed in Table 2. Figure 4 and Table 2 demonstrate the drastic ice shrinkage from $12058 \times 10^{3} \mathrm{~m}^{2}$ in 1912 to about one-quarter of this area in 1989, with a progressive disintegration (see Fig. 2) of domain A into ice entities 1, 2 and 15-20; of domain D into ice entities 3-8, 10 and 11; and of domain $\mathrm{E}$ into ice entities 12-14. A small but significant detail that might be missed in Figure 4 is the appearance of a rock outcrop in the middle of the Northern Ice Field (ice entity 20 in Table 1), beginning with the 1989 satellite image. Overall, the rate of area change was of the order of $10^{5} \mathrm{~m}^{2} \mathrm{a}^{-1}$, with plausibly smaller rates for the diminished total ice cover in more recent times. Similarly, the largest absolute amounts of area change are found for the larger ice entities.

\section{MODELING OF SOLAR RADIATION}

The radiation model is described in detail in Hastenrath (1984, p. 243-246) and Kruss and Hastenrath (1987), and only a short summary of the essentials is given here. The clear-sky direct solar radiation on a horizontal surface was calculated for the middle of each calendar month from the following information: declination, latitude, hour angle, solar constant and a value of unity for the "old" Linke turbidity factor $T$, supported by our radiation measurements on nearby Mount Kenya. Again based on measurements during our expeditions, the global radiation at clear sky was set $5 \%$ larger than the direct radiation value. Global

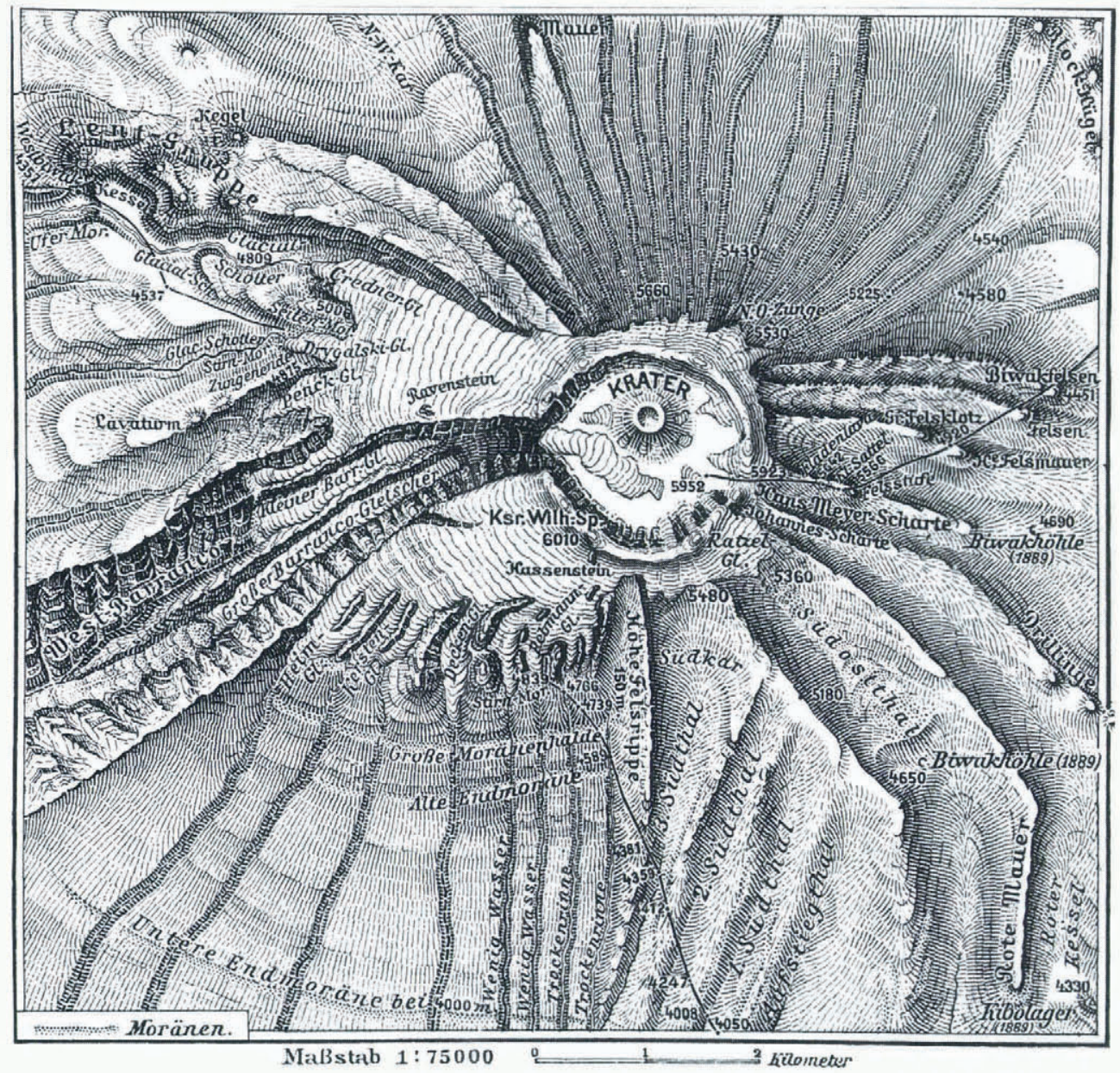

Fig. 3. Sketch-map of ice cover on Kibo in 1898 by Meyer (1900). Scale 1: 75000. 


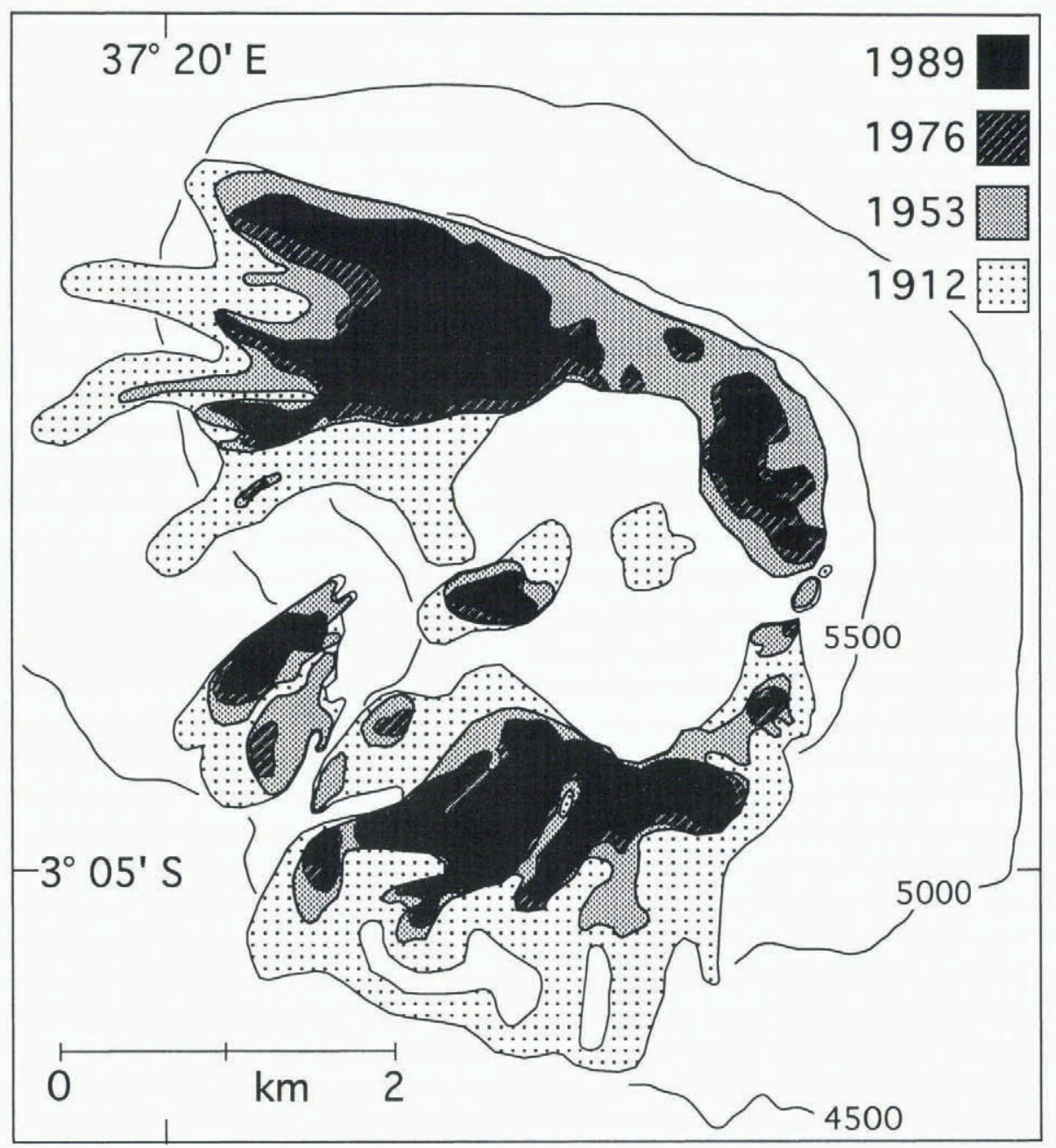

Fig. 4. Map of ice extent on Kibo, in 1912, 1953, 1976 and 1989. Scale 1:50 000.

radiation under cloudy sky was calculated from the clearsky value using an empirical coefficient accounting for fractional cloud cover.

The radiation model was then combined with the digitized terrain topography of Kilimanjaro. For all gridpoints in a $25 \mathrm{~m}$ spacing, the direct-beam solar radiation was calculated for the middle of all calendar months and the midpoints of all daylight hours, using as input the elevation of all gridpoints. Shading by topographic obstacles was included for each gridpoint, using computed solar elevation and azimuth angle and the input grid-point elevation. The grid of elevation values was scanned along the solar azimuth line radiating from each gridpoint to determine if the land surface rises above the solar elevation angle, thus blocking the direct beam.

Calculations were performed for two scenarios. The pat- tern for year-round clear-sky conditions is depicted in Figure 5a. Shown in Figure 5b are the results for clear sky in the morning and five-tenths cloudiness in the afternoon. In both panels, the approximately horizontal surfaces of the crater stand out with strong insolation. This pattern, and not merely geothermal effects, may explain the large ice-free surfaces in the crater. Figure 5a shows for the steeper western slopes less radiation than for the eastern side. This zonal asymmetry is further accentuated in Figure 5b, illustrating the effect of the diurnal cycle of cloudiness associated with local circulation systems on the distribution of solar radiation received. In an effort to compact the information in Figure $5 \mathrm{a}$ and b, radiation values were averaged over the area of each quadrant contained between the 5600 and $5000 \mathrm{~m}$ height contours, encompassing broadly the mountain slopes between the crater rim and lower end of the

Table 2. Variations of ice-covered area evaluated from the map Figure 4 for the domains $A-G$ defined in Figure 2

\begin{tabular}{|c|c|c|c|c|c|c|c|c|}
\hline & $A$ & $B$ & $C$ & $D$ & $E$ & $F$ & $G$ & Total \\
\hline \multicolumn{9}{|c|}{ A. Areas $\left(10^{3} \mathrm{~m}^{2}\right)$} \\
\hline 1912 & 5676 & 3 & 27 & 5011 & 811 & 372 & 158 & 12058 \\
\hline 1953 & 3829 & - & 16 & 2156 & 493 & 181 & - & 6675 \\
\hline 1976 & 2440 & - & - & 1409 & 209 & 113 & - & 4171 \\
\hline 1989 & 1900 & & - & 1168 & 147 & 90 & & 3305 \\
\hline \multicolumn{9}{|c|}{ B. Rates of area change $\left(10^{5} \mathrm{~m}^{2} \mathrm{a}^{-1}\right)$} \\
\hline $1912-53$ & 45 & 0 & 0 & 69 & 8 & 5 & 4 & 131 \\
\hline $1953-76$ & 62 & & 1 & 33 & 13 & 3 & - & 112 \\
\hline $1976-89$ & 39 & - & - & 17 & 5 & 2 & - & 63 \\
\hline
\end{tabular}



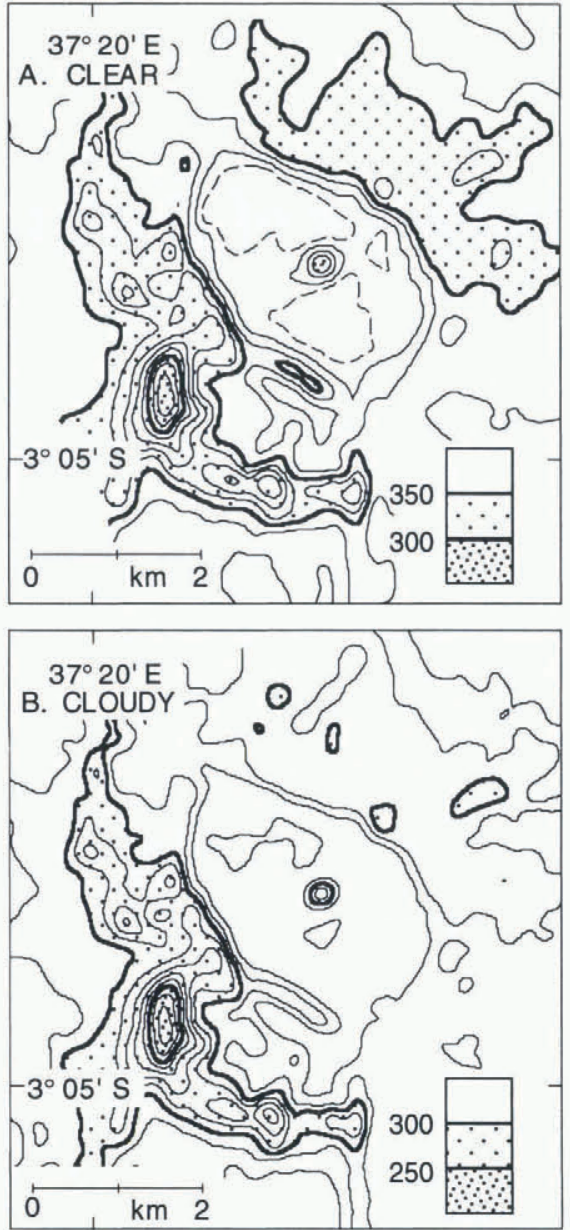

Fig. 5. Maps of modeled annual mean downward-directed solar radiation on a horizontal surface, with contour spacing of $10 \mathrm{~W} \mathrm{~m}^{-2}$ except for dashed lines in crater at $5 \mathrm{~W} \mathrm{~m}^{2}$ : (a) clear sky; ( b ) clear sky in the morning and five-tenths cloudiness in the afternoon. Scale 1:100000.

glaciers (see Fig. 2). Values differed little between north and south, but more substantially between east and west. For clear sky (Fig. 5a), values were $352 \mathrm{~W} \mathrm{~m}^{-2}$ for east against $339 \mathrm{~W} \mathrm{~m}^{-2}$ for west, and in the cloudy case $310 \mathrm{~W} \mathrm{~m}^{2}$ for east contrasted with $292 \mathrm{~W} \mathrm{~m}^{-2}$ for west. To put the effect of these radiation asymmetries into perspective, note that $10 \mathrm{~W} \mathrm{~m}^{2}$ is sufficient to melt a $1 \mathrm{~m}$ column of ice cover over one mass-budget year.

\section{SUMMARY AND CONCLUSIONS}

In the light of growing concern about the "greenhouse effect" and global change, a reconstruction of the glacier retreat on Africa's highest mountain was particularly timely. Spanning a century, this endeavor had to rely on a diversity of observational sources, encompassing a sketch from 1898 , terrestrial-photogrammetric mappings in 1912 and 1953 and satellite images in 1976 and 1989. Basic to this effort was the construction of a digital terrain model from the OTS Tanganyika Government, 1972). With reference to this terrain model the satellite scenes were evaluated, using ground features prominent on both the satellite images and the OTS. The meridional contrast in the ice distribution on Kibo ap- pears to be primarily due to the more abundant precipitation on the southern flanks, although the insolation for this mountain to the south of the Equator would contribute in the same sense. The more prominent zonal asymmetry in the ice extent is understandable from radiation modeling. This yielded particularly large insolation for the approximately horizontal and ice-free surfaces of the crater, and smaller radiation values for the steeper western slopes than for the eastern side. This zonal contrast is accentuated by the enhanced afternoon cloudiness associated with local diurnal circulations, which shields the glaciers on the western slopes from insolation. The total ice cover diminished from $12058 \times 10^{3} \mathrm{~m}^{2}$ in 1912 to about one-quarter of this in 1989, and the three largest coherent ice domains disintegrated into numerous smaller entities. Thus the study documents a drastic and monotonic ice recession throughout the 20th century, consistent with the other glaciated high mountain regions of the tropics. It is intended to monitor the further evolution of the ice cover on Kilimanjaro from satellite sensing in the late 1990s.

\section{ACKNOWLEDGEMENT}

This study was supported by U.S. National Science Foundation grant EAR-9217211.

\section{REFERENCES}

Coutts, H. H. 1969. Rainfall of the Kilimanjaro area. Weather, 24, 66-69. Hacberli, W. and M. Hoelzle, eds. 1993. Fluctuations of glaciers 1985-1990 ( Vol. VI). Wallingford, Oxon., IAHS Press; Nairobi, UNEP; Paris, Unesco.

Haeberli, W., E. Herren and M. Hoclzle, eds, 1993. Glacier Mass Balance Bulletin. Bulletin No.2 (1990 1991). Wallingford, Oxon., IAHS Press; Nairobi, UNEP; Paris, Unesco.

Hastenrath, S. 1981. The glaciation of the Ecuadorian Andes. Rotterdam, A.A. Balkema.

Hastenrath, S. 1984. The glaciers of equatorial East Africa. Dordrecht, etc., D. Reidel Publishing Co.

Hastenrath, S. 1991. The climate of Mount Kenya and Kilimanjaro. In Allan, I., ed. Guide to Mount Kenya and Kilimanjaro. Nairobi, Mountain Club of Kenya, 33-36.

Humphries, D.W. 1953. Interim report of the glaciology and meteorology of Kilimanjaro, Tanganyika territory. Dar-es-Salaam, Geological Survey of Tanganyika.

Klute, F. 1914. Forschungen am Kilimandscharo im Jahre 1912. Geographische Zeitschrift, 20, 496-505.

Klute, F. 1920. Ergebnisse der Forschungen am Kilimandscharo 1912. Berlin, ReimerVohsen.

Klute, F. 1921. Die stereophotogrammetrische Aufnahme der Hochregionen des Kilimandscharo. Zeitschrift der Gesellschaft für Erdkunde zu Berlin, 56, $144-151$.

Klute, F, and E. Oehler. 1922. Karte der Hochregionen des Kilimandscharo-Gebirges nach stereophotogrammetrischen Aufnahme 1912. Scale 1:50000. Zeitschrifl für Vulkanologie, 6, 198.

Kruss, P. D. and S. Hastenrath. 1987. The role of radiation geometry in the climate response of Mount Kenya's glaciers. Part 1. Horizontal reference surfaces. J. Climatol., 7 (5), 493-505.

Marvin, J.W., M. L. Labovitz and R. Wolfe. 1987. Derivation of a fast algorithm to account for distortions due to terrain in earth-viewing satellite sensor images. IEEE Trans. Geosci. Remote Sensing, GE-25 (2), 244-251.

Meyer, H. 1890. Ostafrikanische Gletscherfahrten. Leipzig, Duncker und Humblot.

Meyer, H. 1900. Der Kïlimandscharo. Berlin, Reimer-Vohsen.

Tanganyika Government. 1972. Kilimanjaro. Dar-es-Salaam, Tanganyika Government. Surveys and Mapping Division. (DOS 422, Series Y 742, Sheet 56/2, Scale 1:50000.

World Meteorological Organization. 1988. World climate research programme. Geneva, World Meteorological Organization Secretariat. (WCRP-5, WMOTD 215. 